\section{Pneumomediastinum after Facial Bone Contouring Surgery}

Kun-Woon Yoo, Kyung Sik Kim

Department of Plastic and Reconstructive Surgery, Myongji Hospital, Kwandong University College of Medicine, Goyang, Korea

Correspondence: Kyung Sik Kim

Department of Plastic and Reconstructive Surgery, Myong-Ji Hospital, Kwandong University College of Medicine, 55 Hwasu-ro 14beon-gil, Deokyang-gu, Goyang 412-826, Korea

Tel: +82-31-910-7320, Fax: +82-31-910-7814

E-mail: kskimps@naver.com

No potential conflict of interest relevant to this article was reported.

Received: 10 Feb 2014 • Revised: 24 Feb 2014 • Accepted: 28 Feb 2014 pISSN: 2234-6163• elSSN: 2234-6171

http://dx.doi.org/10.5999/aps.2014.41.4.443 • Arch Plast Surg 2014:41:443-445

Copyright @ 2014 The Korean Society of Plastic and Reconstructive Surgeons

This is an Open Access article distributed under the terms of the Creative Commons

Attribution Non-Commercial License (http://creativecommons.org/licenses/by-nc/3.0/)

which permits unrestricted non-commercial use, distribution, and reproduction in any

medium, provided the original work is properly cited.

Pneumomediastinum is a rare complication that occurs after facial bone contouring surgery. However, it is considered as a life-threatening complication, and it is difficult to prevent pneumomediastinum as it occurs due to unknown or unexpected reasons.

There are two suggestive causes of pneumomediastinum that occurs in association with facial bone contouring surgery. First,

pneumomediastinum could occur due to the influx of air into the mediastinum, which is caused by the air dissecting along the fascial plane due to injury to the cervical fascia or chest wall or infection. Second, pneumomediastinum could occur due to spontaneous alveolar rupture due to increased intra-alveolar pressure $[1,2]$. The authors encountered a patient who unexpectedly developed pneumomediastinum after facial bone contouring surgery. Accordingly, we report the causes, clinical manifestations, and treatment of pneumomediastinum that occurred after facial bone contouring surgery.

A 38-year-old foreign woman visited the hospital for a prominent zygomatic bone and square jaw.

Her height was $160 \mathrm{~cm}$ and weight was $53 \mathrm{~kg}$, and she did not have any specific medical history. Preoperative examination showed normal findings. The patient underwent zygomatic bone reduction with L-shape osteotomy, mandibular angle reduction, and horizontal reduction genioplasty. The patient had stable vital signs during surgery, and no particular event occurred during surgery. After surgery, the patient was transferred to the recovery room without performing extubation to ensure a secure airway. Vital signs, which were checked immediately after surgery in the recovery room, showed normal, and pulse oximeter saturation $\left(\mathrm{SpO}_{2}\right)$ of $100 \%$. Despite stable vital signs, the patient complained of severe discomfort and tried to self-extubate. At one hour after surgery, the patient showed signs of respiratory distress. The $\mathrm{SpO}_{2}$ decreased to $92 \%$, and mild perioral cyanosis was noted. Arterial blood gas analysis (ABGA) and Chest X-ray (CXR) were performed with Air mask bag unit ventilation. Approximately 30 seconds later, the patient's condition improved. The result of $A B G A$ showed a $\mathrm{pH}$ of 7.25, $\mathrm{PCO}_{2}$ of $35 \mathrm{~mm} \mathrm{Hg}, \mathrm{PO}_{2}$ of $80 \mathrm{~mm} \mathrm{Hg}$, and $\mathrm{SpO}_{2}$ of $93 \%$. The patient had an oxygen saturation of $95 \%$ under the maintenance of $5 \mathrm{~L} \mathrm{O}_{2}$ with T-piece. Physical examination showed that the patient had recovered from perioral cyanosis, but she had developed subcutaneous emphysema with crepitus over the clavicle and axillary area.

Pneumomediastinum, pneumoretroperitoneum, and subcutaneous emphysema were observed on CXR (Fig. 1). After maintenance of $5 \mathrm{~L} \mathrm{O}_{2}$, her respiratory distress decreased, the patient was transferred to the Intensive Care Unit. The patient had $\mathrm{SpO}_{2}$ of $88 \%$ to $92 \%$ under maintenance of $5 \mathrm{~L} \mathrm{O}_{2}$ with T-piece, and therefore, it was increased to $8 \mathrm{~L} \mathrm{O}_{2}$ for performing high-pressure oxygen in collaboration with the Department of Thoracic and Cardiovascular Surgery. On the first day after surgery, CXR showed that pneumomediastinum and pneumoretroperitoneum were improved. Since the patient maintained a stable

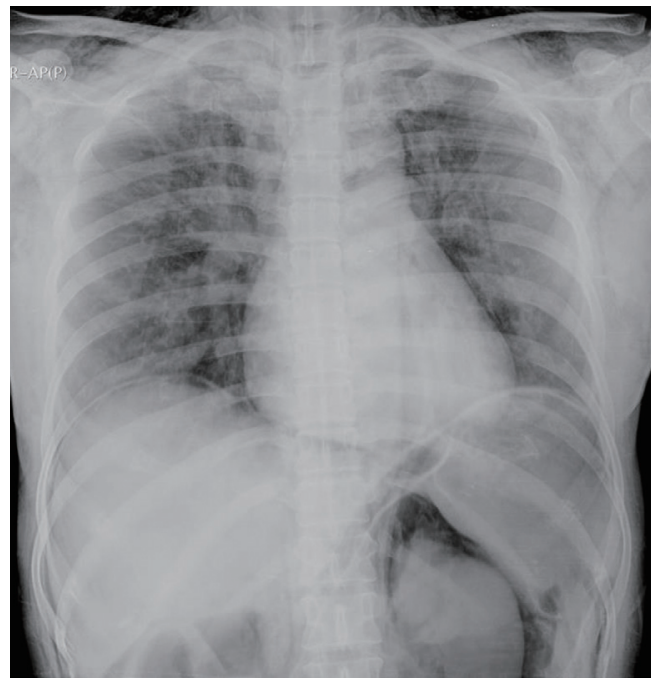

Fig. 1.

Pneumomediastinum and pneumoretroperitoneum were observed on the chest X-ray (antero-posterio) that was performed immediately after the surgery. 
Fig. 2.

Pneumomediastinum with pneumoretroperitoneum was significantly improved compared with the status of the previous day, on the chest

$\mathrm{X}$-ray (antero-posterio) that was performed on the first day after surgery.

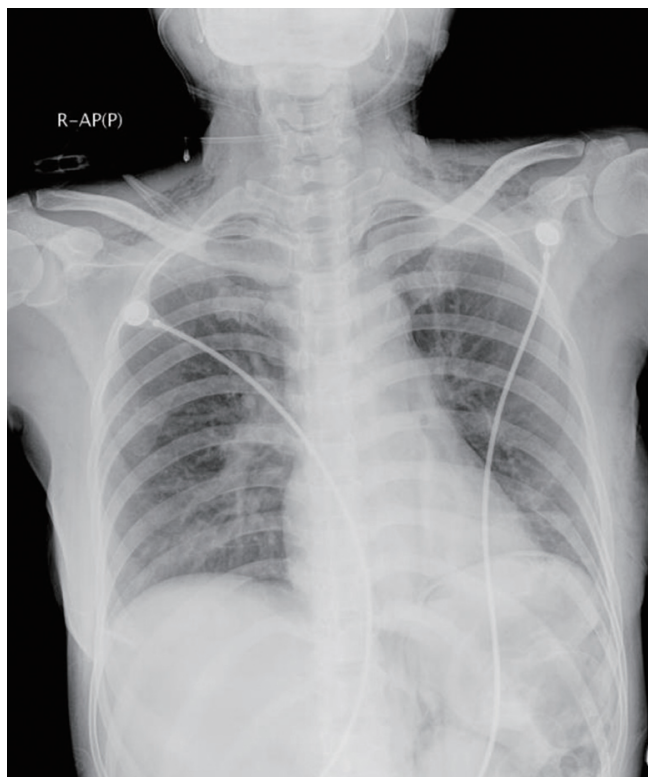

respiratory status, it was decided to perform extubation and $8 \mathrm{~L} \mathrm{O}_{2}$ was maintained using an $\mathrm{O}_{2}$ mask (Fig. 2). One hour after extubation, vital sign was stable. Therefore, the patient was transferred to the general ward. The authors recommended chest and abdomen computed tomography for an accurate evaluation of the causes, but the patient refused. On follow up CXR that was performed 3 days after the surgery, pneumomediastinum and pneumoperitoneum were not observed. In addition, no additional complications developed until the patient was discharged one week later (Fig. 3).

Pneumomediastinum can be divided into two groups. One is spontaneous pneumomediastinum (SPM) that occurs due to unknown reasons; and the other is secondary pneumomediastinum, which occurs due to reasonable causes such as trauma, intrathoracic infections through the deep facial planes in the neck (such as Lincoln's highway), and injury to the aerodigestive tract [2,3]. Explain briefly Lincoln's highway, it is formed by all three layers of deep neck fascia and most commonly secondary to spread of infection from adjacent fascial spaces. So complications of infection in this space include pneumothorax and pneumomediastinum. Both pneumomediastinum can occur after facial bone contouring surgery. In this report, the preoperative CXR was normal. In addition, damage to the cervical fascia or chest wall were not observed during surgery. The ventilator pressure during anesthesia was within the normal range. Furthermore, no specific finding was observed in the $\mathrm{ABGA}$ and $\mathrm{SpO}_{2}$ monitoring that were continuously

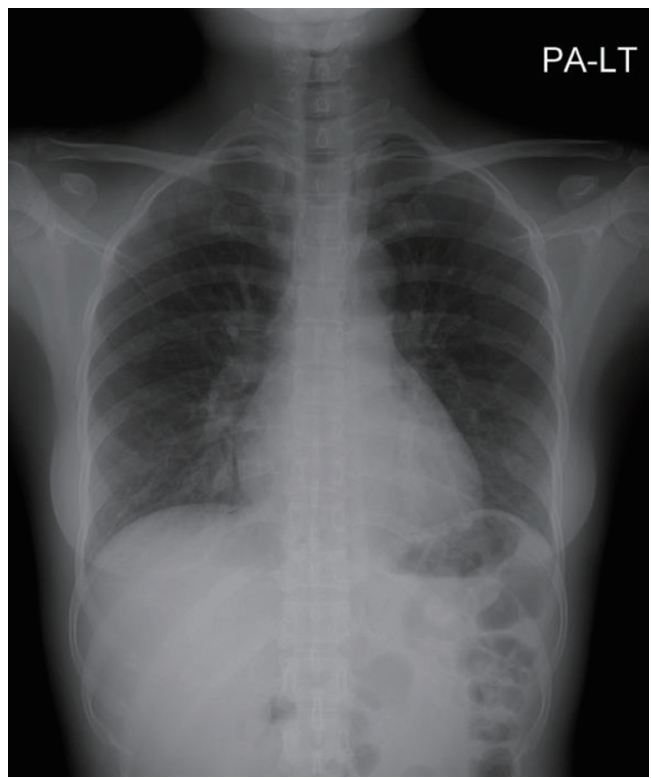

Fig. 3.

Pneumomediastinum and pneumoretroperitoneum were not observed on the chest $X$-ray (CXR) (posteroanterior) that was performed 3 days after the surgery, and this CXR showed normal findings.

performed during the surgery. Therefore, we cannot rule out the possibility of spontaneous rupture due to increased intra-thoracic pressure caused by irritation during the postoperative recovery. Also, a small injury to the fascia, which was not detected during genioplasty or mandible angle reduction, could have caused pneumomediastinum. Previous studies also reported that pneumomediastinum occurred after facial trauma or orthognathic surgery, but in most of the cases, pneumomediastinum was caused as a result of the air dissecting along the facial plane [4]. In this study, although the possibility of injury to the cervical fascia, and the possibility of spontaneous alveolar rupture, which was caused by increased intrathoracic pressure due to the patient's anxiety in the recovery room, could not be ruled out. Pneumomediastinum was more likely to be caused by spontaneous alveolar rupture considering that subcutaneous emphysema involving the axillary area, there was no occurrence of emphysema of the neck and face, and the patient's irritation. Prevention of injury to the cervical fascia during facial bone contouring surgery should be the first priority. However, as there is a possibility of the occurrence of unexpected spontaneous pneumomediastinum, it is important not to perform extubation before the patients become conscious or there is recovery of spontaneous breathing. Secretion drainage is also important after surgery. For 
preventing patient's anxiety, it is important to provide a detailed explanation about the surgery and postoperative discomfort to the patients. In particular, the number of foreign patients undergoing facial bone contouring surgery is increasing. As foreign patients might be more concerned about undergoing surgery, a detailed explanation before the surgery or availability of interpreter service in the recovery room will be very helpful for reducing the patient's anxiety level. Thus, in addition to postoperative evaluation, continuation of intubation, proper treatment, and reduction of patient's anxiety level are also necessary for preventing pneumomediastinum.

\section{Reference}

1. Kim T, Kim JY, Woo YC, et al. Pneumomediastinum and pneumothorax after orthognathic surgery: a case report. Korean J Anesthesiol 2010;59:S242-5.

2. Flood TR. Mediastinal emphysema complicating a zygomatic fracture: a case report and review of the literature. Br J Oral Maxillofac Surg 1988;26:141-8.

3. Caceres M, Ali SZ, Braud R, et al. Spontaneous pneumomediastinum: a comparative study and review of the literature. Ann Thorac Surg 2008;86:962-6.

4. St-Hilaire H, Montazem AH, Diamond J.

Pneumomediastinum after orthognathic surgery. J Oral

Maxillofac Surg 2004;62:892-4. 